\title{
A Grounded Analysis of Player-Described Board Game Immersion
}

\author{
Timea Farkas \\ Goldsmiths, University of London \\ London, United Kingdom \\ tfark001@gold.ac.uk \\ Paul Cairns \\ University of York \\ York, United Kingdom \\ paul.cairns@york.ac.uk
}

\author{
Sarah Wiseman \\ Goldsmiths, University of London \\ London, United Kingdom \\ s.wiseman@gold.ac.uk \\ Rebecca Fiebrink \\ Creative Computing Institute, \\ University of the Arts London \\ London, United Kingdom \\ r.fiebrink@arts.ac.uk
}

\begin{abstract}
Substantial research has explored the experience of immersion in digital games, but it is unclear whether this phenomenon extends to other game genres such as board games. Immersion is a concept widely discussed in the board game community by both developers and players and yet there is relatively little research in the area. This paper presents a grounded theory analysis of board game players' online discussions of immersion. This data is augmented by interviews with five board game players describing their experiences of immersion. The resultant analysis highlights that board game players discuss immersion in terms of both engrossment in the challenge of the game, and submergence within the game world the board game creates. We also focus on elements of game play which players reported in helping and hindering their immersion; importantly these elements do not always come from the game itself. We conclude that board game immersion shares similarities with the literature on immersion in digital games, despite the lack of multimedia interaction.
\end{abstract}

\section{CCS CONCEPTS}

- Human-centered computing $\rightarrow$ Human computer interaction (HCI); • HCI design and evaluation methods $\rightarrow$ User studies.

Permission to make digital or hard copies of all or part of this work for personal or classroom use is granted without fee provided that copies are not made or distributed for profit or commercial advantage and that copies bear this notice and the full citation on the first page. Copyrights for components of this work owned by others than the author(s) must be honored. Abstracting with credit is permitted. To copy otherwise, or republish, to post on servers or to redistribute to lists, requires prior specific permission and/or a fee. Request permissions from permissions@acm.org. CHI PLAY '20, November 2-4, 2020, Virtual Event, Canada

(c) 2020 Copyright held by the owner/author(s). Publication rights licensed to ACM.

ACM ISBN 978-1-4503-8074-4/20/11...\$15.00

https://doi.org/10.1145/3410404.3414224

\section{KEYWORDS}

Immersion; Tabletop Games; Player Experience; Board Games

ACM Reference Format:

Timea Farkas, Sarah Wiseman, Paul Cairns, and Rebecca Fiebrink. 2020. A Grounded Analysis of Player-Described Board Game Immersion. In Proceedings of the Annual Symposium on ComputerHuman Interaction in Play (CHI PLAY '20), November 2-4, 2020, Virtual Event, Canada. ACM, New York, NY, USA, 14 pages. https: //doi.org/10.1145/3410404.3414224

\section{INTRODUCTION}

Immersive gameplay is an important aspect in how video games are discussed by players and the academic community alike [20, 27, 28, 32]. These groups however have differing understandings of the word, and theories about causes and sensations of immersion are varied in academic literature[41]. Immersion is not the sole preserve of the video game research community, it is discussed within films and other media, such as tabletop role-playing [11] and theatre[64] highlighting that the term can be applied in many domains.

Board games are currently a popular hobby: the international board game convention Essen Spiel had 209,000 visitors in 2019 [62], while board games have surpassed video games in funding numbers on crowd-sourcing website Kickstarter with a total of 165 million USD raised in 2018 [31]. The term "immersive" is often used as a selling point by publishers releasing new games [26, 44, 56, 60] which suggests it is something that players are interested in. Whilst there is an abundance of literature about immersion in video games, there is currently a lack of research looking at immersion within analogue tabletop games.

Some of the elements of video games which are believed to make them immersive are also shared with board games, including problem solving [12, 28] and world building [28, 38]. However board games clearly lack other potentially key features for immersion such as high realism of the experience [66]. When board gamers discuss immersion, are they 
talking about and experiencing the same sensations as in video games? Technology is increasingly beginning to feature within this previously analogue genre [19, 35, 53, 61], which may suggest there are overlaps, but this is a relatively new trend in board games. Can the traditional board game elicit immersion and does it look anything like the immersion discussed and studied within the video game literature?

In this paper we explore how immersion is described by board gamers and look at the features that players report as helping and hindering this experience. We contribute two theories: first, the Conditions required for immersion in a board game and second, a description of the variety of Experiences of immersion once it is achieved. We find many similarities with video game immersion with respect to the cognitive experience, and find that even the board game "system" can contribute to a sense of immersion through design decisions such as mechanics and physical pieces. It appears that confusion about how to define immersion is not solely the preserve of the video game literature, but that board game players themselves also contribute to the nebulous definition of immersion in their field.

\section{BACKGROUND}

\section{Board Games in Research}

Board games have been studied in a variety of fields, ranging from history $[5,43,55,65]$ through psychology $[30,57]$ to artificial intelligence $[13,58]$. These areas of research often view the board game as a tool-to understand ancient civilisations, or as an educational aid for instance. In this way board games are often studied as a byproduct, rather than as a concept in and of themselves. More recently however, there has been a growing body of research specialising in exploring the extensive library of modern, hobby board games and their players [8-10, 34, 48, 51].

The area of modern board game research highlights the rich and varied communities that exist within the area, and therefore increasingly draw a distinction between "casual" and "hobby" board gamers when referring to players. Arnaudo [2], for example, defines a hobby board gamer as " $a$ person who considers playing board games as a hobby of major importance in their life", and a hobby board game as "the type of game that hobby board gamers mainly play and enjoy". Rogerson et al. [49, 50] also draws a distinction between casual and "serious" gamers, where the latter is considered the equivalent of a hobby board gamer. The ability to draw such a distinction between players highlights how "seriously" one can take this form of gaming.

The research of modern board games and their players examines not just play, but its surrounding practices, finding that the collecting, cataloguing and discussing of board games are central characteristics within the hobby. Furthermore, many of these practices happen online through a central "hub" called BoardGameGeek [6], a website which supports these organisational and social practices. According to Rogerson [50], "being a BoardGameGeek is not simply about playing games; in accruing gaming capital, users engage with a specific set of digital practices that support and enable material acts of play, and that invite users to co-create emic information about games and the gaming hobby, even when the user themself sees their engagement with board games as a rejection of technology". Whilst board games are often predominantly an analogue activity in their primary use, the culture surrounding them can be heavily reliant upon technology.

\section{Video Game Immersion}

Within digital game research, immersion is a much studied trait of player experience. This has resulted in a large variety of interdisciplinary contributions towards a collection of diverse definitions.

The term was popularised by Janet Murray as a synonym for submergence into another, imaginary world, where transportation can occur because of the human ability to build imaginary worlds when presented with strong narrative elements [40].

Since the introduction of the term within video games literature, the field has benefited from immense technological advancements, meaning the discussions around immersion have changed. Virtual reality research for instance takes the notion a step further, dividing the experience into immersion and presence, where immersion is a reflection on the realism of the virtual world, while presence is the player's feeling of inhabiting this world. Immersion, therefore, is bound to the level of fidelity the technology can provide while presence is directly connected to the experience of the player [59]. Both Murray's emphasis on narrative as a requirement of immersion and VR creators' focus on technology that produces high fidelity experiences are challenged by McMahan [39], who argues that the conditions of immersion are related to how similar the presented world and the expected world are, how much impact the player can make on said world, and whether the world achieves consistency in its rules.

Definitions of immersion become more player-centric in other areas of video games research. Examples of this include Brown and Cairns' [12] "scale of involvement" or Ermi and Mayra's [28] three modes of immersion. Both of these studies collected data from players describing their experiences, recognising that not all players might experience immersion in the same way. The main difference in the findings between the two resulting immersion models is that while Brown and Cairns [12] constructed a linear model of immersion-in which a hierarchy of increasingly involved experiences are described-Ermi and Mayra [28] established 
a model where the different categories of immersion are not reliant upon each other and therefore do not build upon one another.

Jennett [33], in her investigation into video game immersion, has supported the notion of immersion being a multilayered experience. Her definition suggests that immersion is a "cognitive phenomenon", expanding on both Brown and Cairns' "involvement model" and Salen and Zimmerman's description of immersion as a "multi-layered state of consciousness" [33].

It is clear then that there are multiple different approaches and definitions of immersion within video game literature. For a comprehensive review, please see Nilsson et al. [41]. One of the major contributions of this review paper is that the authors present categorisations of immersion theories. The two overarching concepts of immersion presented are immersion as a property of the system and immersion as a cognitive response in players. The cognitive immersion category is further sub-divided as either a response to perception, challenge or narrative. When considering how video game immersion literature could translate to board games, it seems that the cognitive approaches to immersion could prove viable. The challenge or narrative of a game for instance do not necessarily rely upon any technological features. Systemrelated properties of immersion however could prove less relevant to board games. If immersion is considered to be something reliant upon high fidelity audio and visual experiences, it seems that the standard analogue tabletop game would not be able to achieve this.

More recent immersion research has aimed to test these theories in an applied manner. Cairns et al. [14], for example, set out to examine the relationship between presence and immersion-namely, whether increasing one would result in an increase in the other-with a two-factor experiment. Their findings show that presence has no effect on immersion, and that a first person perspective which greatly contributes to presence [66], actually has no effect on immersion. Music and time pressure, on the other hand, were both factors which influenced immersion. This result has important implications for the consideration of immersion in board games, as it highlights that graphical fidelity is not a necessary part of immersion within video games, and thus may not be necessary within board games.

There is evidence to suggest that player understanding of immersion is also not necessarily related to presence. In a study by Denisova et al. [20] which compares player experience questionnaires, researchers found that participants, when describing either immersion or engagement, described largely similar aspects of the overall player experience. This suggests that immersion may be more akin to engagement by players than to presence.
While some researchers question the continued relevance of immersion as a concept within player experience $[15,54]-$ or at least emphasise the importance of giving a clear definition of what is meant by immersion in future papers [16]-in this paper we choose to discuss board game immersion as it appears to be an important topic with the analogue gaming community, arguing that players and their interests are a central part of player experience research.

\section{Board Game Immersion}

Arguably, there is little research into board game immersion. Arnaudo [2] has investigated the concept of flow in hobby board games. Whilst flow in itself is generally regarded as a separate experience from immersion, there are certain overlapping characteristics which are recognised by researchers $[12,24,32]$. In the work, Arnaudo considers flow as a form of immersion, identifying "hobbyist" (more involved) board games to be more likely to facilitate flow experiences due to higher complexity.

Wake attempts to explore board game immersion from a theoretical perspective[63]. The research suggests that the physicality of board games may be important to facilitating immersion. Wake highlights that board games are "tactile" experiences in which players constantly share their attention between events happening on the table and events occurring in the surrounding space between the players and theorises that this environment may contribute to an immersive experience. As with early video game immersion research, this work is largely theoretical and lacks player-centric data.

\section{Summary}

The existing research on the topic of board games has not focused heavily on immersion. Work that does consider the idea has been largely theoretical. It may be possible to draw from the video game immersion theory, however the fundamental differences between the two genres of game may mean this is not possible. For instance, some research in digital game literature suggests that fidelity of the media is important for encouraging immersion. It is clear that a tabletop game cannot replicate this level of realism which raises questions about whether video game immersion research is applicable in this domain. It may therefore be the case that an understanding of immersion in board games requires a different framework.

In this paper, we aim to understand how board game players describe immersion in analogue games. Using data collected from hobbyist gamer forums and interviews, we conduct an analysis and construct a theory describing how board gamers experience immersion. In addition, we explore the factors that both help and hinder this immersion. Our contributions include: 
- A spectrum describing varying player-reported experiences of board game immersion.

- A matrix of conditions which can have positive and negative effects on immersion. This also highlights how immersion is affected by both in- and out-of-game factors.

- A preliminary theory that immersion is a function of not the player, nor the game, but a combination of the two.

\section{METHODOLOGY}

\section{Forum Data}

Data was collected from pre-existing discussions on online board game forums. Specialist forums-such as BoardGameGeek or Reddit's r/boardgames-play an extensive role in discussing the purchasing, collecting and play experience of tabletop games. Previous research into online consumer behaviour has shown that Electronic Word of Mouth (EWOM) has a great impact on the sales of media products such as video games or books [18] [67]. While there is no similar research regarding board games, BoardGameGeek's surpassing of the five million mark for unique visitors [6] and r/boardgames currently having 1.4 million registered users [47] show the importance of electronic discussions to analogue gamer communities [50]. We acknowledge here, and will discuss in more detail in the limitations, that this sampling of data may overly represent board game players who are not casual gamers. [50]

The first data set was retrieved from a pre-existing discussion thread on a board game related subreddit. Reddit is a social media site that allows users to discuss media or questions in the form of comment chains. A subreddit is an area for users who are interested in a particular topic. Here we chose a discussion in $\mathrm{r}$ /boardgames where respondents answered the user-posted prompt "What is the most immersive game you have ever played?" [45]. In total there were 320 replies to the question, which were gathered into the data set. 220 of these replies were removed from the data set for the following reasons: they either did not provide data on why the game was considered immersive-for instance if the comment simply noted the name of the game and nothing else-or were reactions to another comment, steering from the original discussion. In total, the remaining replies contributed 100 sampled sources. It is assumed that the majority of comments are from unique users, however, due to many users remaining anonymous-without a unique username-it is impossible to tell.

The second data set was theoretically sampled during the coding of the first data set, and consisted of an additional 110 comments retrieved from another reddit discussion thread-with the prompted question of "What is the most immersive game you've played? What game really makes you feel like you are in that world?" [46]-alongside 13 comments from BoardGameGeek, with the prompted question of "What boardgames do you find to be the most immersive? And why?" [7].

\section{Interviews}

The forum posts were collected from discussions that were initiated by users on the sites and not by researchers. Furthermore, the discussions were one to three years old, and as a result were no longer active. For these reasons, there was no ability to discuss the users' responses to the questions regarding board game immersion. Therefore, a third data set-an interview study-was planned to allow researchers to investigate in more depth how board game players experienced immersion. Five participants were recruited for the interview study: two British, two American and one MexicanAmerican, all between the age of 20-50. Four participants were sampled through Twitter based on their regular engagement in board game discussions through various social media platforms and one was recruited through an open call sent to board gaming groups by email. Three participants identified as men and two as women. Interviews were semi-structured and started with asking players what their most immersive board game experience was, replicating the original question from the forum discussions. While followup questions depended on the direction of each individual discussion, all participants were asked to give their own definition of immersion, whether they have had an experience when something broke or prevented immersion, if they have done anything in the past to enhance immersion and whether immersion was important to them.

\section{Grounded Theory}

We employed a standard approach to Grounded Theory following Charmaz [17]. Initial codes emerged from terms frequently used by players themselves in the forum commentssuch as game mechanics, art, story or game pieces-which led to a more focused, theoretical sampling of the second data set and design of interview questions. Simultaneously, the initial codes were refined and grouped into more comprehensive categories, which-after further refinement-became the final categories used in our Results and Discussion sections.

As per Charmaz, data collection, analysis and revisiting of data formed a continuous circle of discussions between three researchers (as opposed to a linear approach), resulting in constantly refining our theories through the process.

\section{Ethical Considerations}

We include the original user quotes from forums to support clarity and interpretability of the paper. As per the guidance from BPS Ethics Guidelines for Internet-Mediated research 
[36], we see that forum data is in the public domain and believe our use of this data does not contravene users' expectations, and no damaging effect is anticipated from the ability to link a quote to its original forum post.

\section{RESULTS}

When analysing the forum data, it became apparent that when discussing immersion in board games players talked about two different aspects. Some players when describing the most immersive board games chose to elaborate on exactly which features they found to be conducive to achieving immersion. These players did not appear concerned with the definition of immersion itself, only with the factors which affect it. Other players however, chose to share a game that they found to be immersive and described how it felt to become immersed in the game. Rather than focusing on aspects which contributed to the immersion, these players aimed to describe and explore what was intended by the undefined term 'immersion'.

Our resultant theory generation therefore produced two overarching categories:

(1) Conditions of immersion - factors which are required for immersion to occur, such as traits of games and behaviours of players.

(2) Experiences of immersion - where players described the qualities of the immersive experience itself.

\section{Conditions of Immersion}

Conditions of immersion are the factors that players require to be present in order to achieve immersion. Conditions reported by players included features of the games themselves and additionally aspects of game play outside of the game, for instance the actions of other players. We distinguish these two types of condition as In-Game and Out-of-Game conditions respectively.

We also noted that players discussed positive and negative conditions for immersion. Both In-Game and Out-of-Game can be positive and negative, positive meaning that the conditions of immersion are met, while negative conditions are those which actively remove a player from immersion.

In-Game Conditions. In-Game conditions describe innate properties of the game that were intentionally included by game designers. This could describe for instance the mechanics or artwork of the game. Other players described how the tactile nature of the game helps their immersion, "I think I need something tactile to feel really immersed. To that end, Eclipse is the one that pops out to me.”. Whereas for another player, the narrative of a game is a key component in feeling immersed, "The storytelling in Above and Below and Near and Far makes for a superb immersive experience.".
Where some players discussed specific aspects of particular games, other players considered certain general conditions to be indicative of whether they would find a game to be immersive. For instance this player explained "When the theme and mechanics come together in a way where they become inseparable, that's where I tend to find the most immersion". Here we see that some players feel they are able to predict their own immersion based upon generalised conditions. This differs from the previous accounts of players who were able to name conditions relating to specific games.

Whilst some players felt that in-game design decisions helped their sense of immersion, others noted that poor design decisions could hinder their ability to feel immersed in a game, for instance this player's account of in-game combat mechanics: "Star Wars: Rebellion - Knocked down slightly because the combat takes you out of the immersion a bit. Matching up colours and icons is certainly not the ideal way to resolve conflict.". Another player reported how poor game design decisions removed their sense of immersion to such an extent that moments which should be emotionally charged were reduced to a simple edit to how the game would play: "[Dead of Winter's scavenging mechanic is] always just a deck of cards and chance. And unless one of the few interesting crossroads cards comes up, I've never been able to get attachment to a character so that their death is anything more than 1 fewer action die."

Some In-Game features of certain games were found to have both positive and negative effects upon immersion depending on the player. One example is the narrative elements of Above and Below [37]. One respondent found the narrative immersive while another player felt that the lack of resolution to story elements prevented their immersion: "Yeah this... made the story aspects of Above \& Below feel hollow to me. You have a moderately interesting little story and situation, and then you... get some small, completely arbitrary bonus because... reasons. It didn't feel very rewarding and it also felt a bit of a jarring conclusion to the situation.".

Out-of-Game Conditions. Out-Of-Game conditions describe factors affecting gameplay which are beyond the control of the game designer. This often refers to the actions of the other players at the table. When players sit down to play a game, they have the option of adhering to rules, ignoring rules, and even adding to them. In addition, players can choose to add layers of role playing to a game which may affect its immersiveness. These aspects, which are not strictly required to play and enjoy the game, are not within the control of the game designer who may have clear intents for how the game should be played but cannot ultimately enforce them.

For some players, immersion was increased by their external knowledge of the game's historical or fictional setting: "Battlestar Galatica. That was probably the most immersed and 
invested into a game. After watching the show then playing the game, just dealing with crisis after crisis each turn was like the show and we were really getting into our roles.".

To increase immersion, some players reported that they adapt their physical environment to better match the game theme, often with music "When I played with my friends I popped on the Last of us soundtrack. It was perfect!" or even clothing and beverages "Oh Merchants and Marauders is fabulously immersive! We've even dressed as seafarers/pirates to play, with a bit of spiced rum on the side and sea shanties playing in the background."

One recurring Out-Of-Game condition that increased immersion which was reported by players was role-playing. For instance "Flash Point: Fire Rescue is amazing for this. We name every firefighter and role-play the entire game.". When all players are in agreement about adding a layer of role-play to the game it creates a more immersive experience for the player. In some games where lore and role-play are already a key component, it is still possible for players to expand upon the given narrative to increase immersion: "[M]y buddy and I really had fun reading all the story paragraphs on cards (in different accents and voices) and crafting hypothetical situations around these characters that would explain why situations took place as they did. [...] the way we played, it really heightened the experience tremendously, and made it so much more fun. Even if we lost horribly." (Discussing Eldritch Horror).

This account highlights how the Out-Of-Game decisions made by players were often made in order to enhance and strengthen an In-Game decision made by the designer. In the previous instance, the player took the narrative provided by the game and chose to expand upon the stories and to add characterisation in the form of voices. One player felt that making these Out-Of-Game decisions was something of a player "responsibility": "I think for any game it takes effort on the players' part to really solidify the theme. In my experience Dead of Winter has been really thematic but my group generally tries to thoroughly narrate the actions taken and events occurring in order to establish continuity with the game's premise."

As with In-Game conditions, it is possible for Out-OfGame decisions to break immersion or prevent it from occurring. For instance when there is disagreement about how the game is best played: "Sherlock Holmes with everyone being a bit silly and role-playing the era is brilliant but with people being too clinical and almost metagaming it's a bit dull."

Whereas this player reports that other players taking the game too seriously (and thus ignoring intentional design decisions) negatively affects their immersion, others reported the opposite effect. When another player is not paying enough attention to the game and not engaging with the rules or mechanic, players reported losing immersion: "No game will ever be able to fully occupy my attention if another player is taking a phone call, while another is checking out another game at another table, and yet another is already talking about what to play next."

While flavour text and story paragraphs are conscious In-Game decisions of the game designer, the Out-of-Game decisions are the responsiblity of the players and can thus choose to ignore careful narrative set up by the designer. Immersion can be hindered for the rest of the group when one or more players ignore flavour text, as this player reported: "I played this with the wrong group, who were just ignoring all the flavor text and powering through. It was a terrible experience, it felt like there was a really cool game under there." while another player further emphasised the role of players themselves in bringing board games into life: "You, as a player, are a part of the theme. If you strip the game from it's theme, cards will be only cards and cubes will be only cubes. I have a friend that does this in everything. Example from Alchemists: "Ok, so I do a red plus and sell it in the thingy", "NO, you concoct a healing potion and sell it to the barbarian on the market"." Discrepancies between players about which aspects of the game to engage with and which to discard are a frequent cause of breaking immersion.

\section{The Immersive Experience}

When players chose to explain their sense of immersionor the feeling they interpreted as immersion-we noted a variety of reported experiences. Here we describe in detail the reports of immersion found within our data sets.

Engrossment. For some players, immersion means being absorbed in gameplay. The emphasis is on the player's role as a "problem solver", where the outcome of the game is largely or solely due to the player's actions. Setting has no effect upon immersion in this instance, only the "problem" or "challenge" is important: I don't find myself immersed in theme very often, but there are several games that immerse me in the gameplay to the point where I don't notice the passage of time.". Whilst it was common for players to note these experiences involved losing track of time, players also associate immersion with stressful and intense experiences: “Go. It's so intense, it's like I melt into the abstract board. After a tight game I'm usually shaking from adrenaline and vow never to play it again. It's a very stressful game for me."

Contextual Engrossment. The feeling of engrossment was enhanced for some players by including or appreciating the context in which the game was being played. Whilst the theming alone did not facilitate immersion, it enhanced the players' sense of challenge-related immersion: "Whenever I play, instead of removing soldiers from the board every time they are killed, I'll leave them in the hex where they di[e]d so that after a battle is over [...] we can see where the most carnage took place. It kind of helps you realize how much went 
into you accomplishing the mission which really adds to the immersion." [Discussing Tide of Iron].

Players are aware of a defined world that surrounds gameplay, but they do not necessarily feel part of this fictional world. Whilst the focus remains on the challenges of the game alongside players' abilities to overcome them, the context affects how the level of challenge is interpreted.

Embodiment. For players who found that both the challenge of the game and the theming or context to be equally important for immersion, their sense of immersion reflected a state of embodiment: "The way [the] campaign is designed makes you feel that you're really a tiny rebel against imperial forces, advancing rebellion one small step at a time. Secondly, it is very very tactical" [Discussing Imperial Assault].

This is a distinct sensation from Contextual Engrossment, where players feel like they are an external force on the game world. For players reporting a sense of Embodiment as immersion, their presence within the game world was key. They reported feeling that they were navigating the problem solving aspect of the game whilst inhabiting a role within that fictional world-for instance making decisions as a character rather than as a player: "Alchemists - It so perfectly mimics academics with all in its glory, that I get into a mindset of an aspiring alchemist every single time. A blast among my academic friends."

Contextual Submergence. Some players placed the world as most important to immersion, and perceived the problem solving aspects of game play to be secondary (but still necessary for immersion). In this sense, one could consider this state of immersion to be the opposite of Contextual Engrossment. For these players, the setting is what allows them to achieve immersion primarily: "You don't necessarily get the feeling of actually doing the things but more like a feeling of being in there (does that even make sense?)" [Discussing T.I.M.E. Stories]

For players who experience Contextual Submergence immersion, whilst they may be making decisions within the game, immersion is not broken if they feel like they don't have influence over the gameplay entirely. They are happy to experience the world more passively and still feel a sense of immersion in the game.

Submergence. Submergence describes players for whom immersion is being fully incorporated into the narrative, setting and unfolding events of a game. For these players, having control over events in the game or solving problems to win is not an important component of immersion, for instance this player discussing the immersion of watching, not playing: "Star Trek Ascendancy feels like you are watching the meta world and politics of Star Trek.”.
As this feeling of immersion does not rely at all upon ingame decision making, a person being immersed this way might not even have to play the game, but rather, be a spectator of others playing: "The game I wanted to say I've never played, I've only watched. And that game [is] Spartacus! That game was the most immersive game I have witnessed. I felt like I was actually watching a group of Dominus scheme, betting, and sending there gladiators/slaves into the arena. As a spectator it felt like I was in the arena stands watching blood spilling and devious schemes being hatched!".

Summary. Through analysis of players' reports of immersion, it was possible to determine that all players were not discussing the same experience. For some, a sense of losing time was deemed immersion whilst for others a feeling of being in the game world was the definition of immersion. The Experience of immersion is therefore distinct between players.

We have chosen to note these differing definitions here through categorisation. We wish to highlight however that we do not believe these categories to be distinct, but rather are way-points along a continuous line of descriptions of immersion, similar to what is seen in [28]. The categories act as illustrative examples of how the two extremes of view with regards to player-reported immersion are not entirely separate and easily distinguished.

\section{Awareness of Immersion}

Whilst these theories are based upon our analysis, it is clear from the data that certain players are also aware of the ambiguity of the term "immersion" in board games. Players stated "Immersion' is an interesting thing, and also very nebulously defined", or "There are two sorts of immersives[sic] here - immersed in the theme/subject matter, and immersed in the gameplay". Where some players were aware of the possible different definitions, others felt that they themselves had the sole correct interpretation of the word, going as far as to call out other players' definitions: "I think you're taking the metaphor of immersion too literally. When people talk about being immersed they don't mean they literally thought they were part of the game's universe", or even questioning other players' experiences: "I think you are holding the term immersion to a higher standard than others in this thread. From my viewpoint, you sound like you do get immersed in games". This indicates that hobbyist board game players are not just aware of immersion as a concept, but are eager to query and question its use and meaning.

\section{Issues with Immersion}

Whilst the majority of respondents experienced immersion in some way or form, there were a few players who did 
not feel board games were a medium able to facilitate immersion for them. One player, for example, attributed this to "board games [not] really [having] enough sensory input or narrative depth that I'd ever call them immersive. It's always still bits on boards with dice and cards." While the same player still experienced getting "deep into a strategy or deep into the social interactions at the table", their Conditions of immersion-"sensory input" and "narrative depth"-were not met by the experience. Whilst board games provided the In-Game attributes of "strategy" and Out-of-Game attributes of "social interactions", the player does not consider these to be their Conditions for immersion. This illustrates how Conditions differ from player to player, enabling immersion for one player while denying it from another.

Another player considered game components to be in the way of Embodiment: "making me feel like a mage? By counting numbers and fid[d]ly bits? Not really...If I wanted immersive, I would read a book", implying that their reason for playing board games is not necessarily for immersion. It is possible for immersion not to happen even when players engage in Out-of-Game practices such as role-playing: "I like being silly and imaginative, yes, but I have never felt like I'm "in" the world of the game. I love a game with good theme and I can do spooky voices or over the top pronouncements of betrayal, but it isn't immersion for me. [...] I've just never had a gaming experience where I have felt like I was in the game instead of playing the game". This comment implies that players can have Conditions of Immersion which are never met by any game experience, creating a constant barrier to immersion for these players.

Lastly, there are players who consider board games to have the ability to facilitate immersion, but believe that immersion cannot compensate for an otherwise bad gaming experience: 'I'd say probably Arkham horror. But that's also a perfect example of why theme and immersion are irrelevant. It's a terrible game, and while you may feel immersed in the world, the lack of gameplay means it's permanently consigned to the shelf". Whilst for some players a driving factor of playing board games is the ability to become immersed, a sense of immersion cannot save a game if the player does not enjoy the base mechanics.

\section{DISCUSSION}

\section{Conditions and Experience of Immersion in Board Games}

Our results indicated that players describe either their conditions for immersion to occur, or the immersive experience itself. We suggest that the Conditions of Immersion are best illustrated as a Matrix, as seen in Figure 1, while the Experience of Immersion itself is best illustrated as a Spectrum, as seen on Figure 2.
We use a matrix to describe conditions for immersion (Figure 1), as there are two major factors which define the conditions: whether they are positive or negative and whether they come from within the game or are something additional brought to the game by players. Board games are played in two spaces simultaneously-on the table with game components, and in the real world, where factors such as other players, one's outside interests, and other elements come into play. Throughout our research, we noted that comments regarding immersion conditions concerned either decisions that the game makers had made (In-Game on the matrix) or actions taken by the players themselves (Out-of-Game on the matrix). We also note that both of these aspects were described in positive and negative terms by players. From this, we determined that the reported conditions for immersion could fit within this two dimensional space. Whilst we feel that all of the comments collected in this study that relate to the conditions of immersion can be placed within the matrix, here (Figure 1) we present example quotes which could be assigned to each of the four quadrants.

We believe both axes are continuous, that is possible for a condition to have a strong or weak positive impact upon immersion for instance. We similarly believe that whilst some features clearly come from within the game (the mechanics of gameplay, the quality of game pieces etc) and some from outside (players choosing to give characters names, putting on music etc), other features are closer to being a combination of both. Take for instance, the player who reported extending the narrative of some in-game characters. The game designer worked to create these three-dimensional characters (In-Game condition) whilst the player chose to add to these stories (Out-Of-Game). In this way, this act was a combined effort from player and game. Since Out-of-Game practices are voluntary, deliberate alterations of how the game plays-including rule modifications to better suit the players-we suggest that these practices present a level of control over the immersion of the game. Board games, due to their inability to reinforce certain boundaries when compared to video games, may result in a new type of player "customisation" of immersion.

Immersion Experiences fell along a spectrum, from engrossment in the challenge of the game, to submergence within the game world. However we note some way-points between these two extremes, and based upon the data analysis, we suggest that immersion for players is comprised of some blend between these two. This spectrum does not comment on the amount of immersion but rather the composition of the immersion. Figure 2 shows a range of immersive experiences and their relative composition of both Challenge and Game World. Challenge relates to how important it is to have influence over the game's outcomes in the form of decision making. For players who experience immersion as 


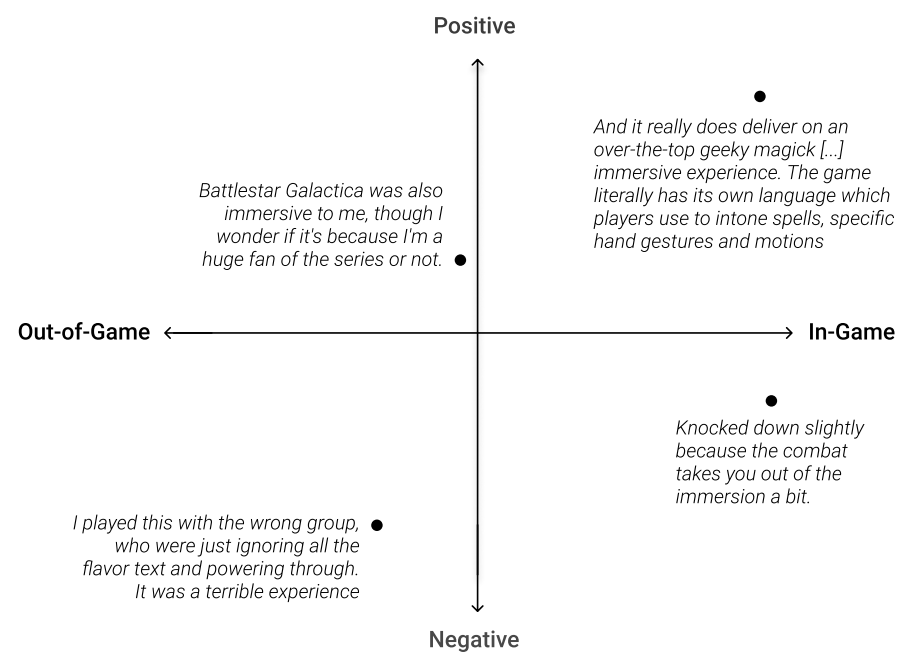

Figure 1: Immersion Conditions: Matrix of conditions required by players to feel a sense of immersion in game, or conditions that lead to a loss of immersion. In-Game Conditions describe those designed by the game maker whilst OutOf-Game Conditions describe those brought to the game by the player. An exemplar quote is presented for each quadrant.

engrossment, this is entirely composed of challenge. Game World relates to all aspects of the fictional world created within the game. This was so strong for some players that all they needed was the narrative to become submerged in the game. They did not even require the ability to make any meaningful changes within the game as they were content to simply watch the game being played, thus requiring no Challenge at all.

Importantly, players also reported a blend between the two game aspects, some reported that immersion came largely from a sense of being in the game world, but was also helped by the presence of challenging game play (Contextual Submergence in Figure 2), others reported becoming immersed in the complex manoeuvres required in the game and found the game theme to be a nice additional touch (Contextual Engrossment in Figure 2). Others still reported that a perfect blend between challenge and game play helped them reach an immersed state (Embodiment in Figure 2). We do not suggest here that absolute percentages can be ascribed to the players studied in this research, but rather we aim to highlight that immersion could be achieved by many different combinations of Challenge and Game World.

We did not find evidence to suggest that immersive experiences are static for each player. That is, we believe that it is possible for the same player to occupy a number of different places on the spectrum; for example, the same player could find immersion within Engrossment in one game while in another game, immersion could look more like Embodiment.

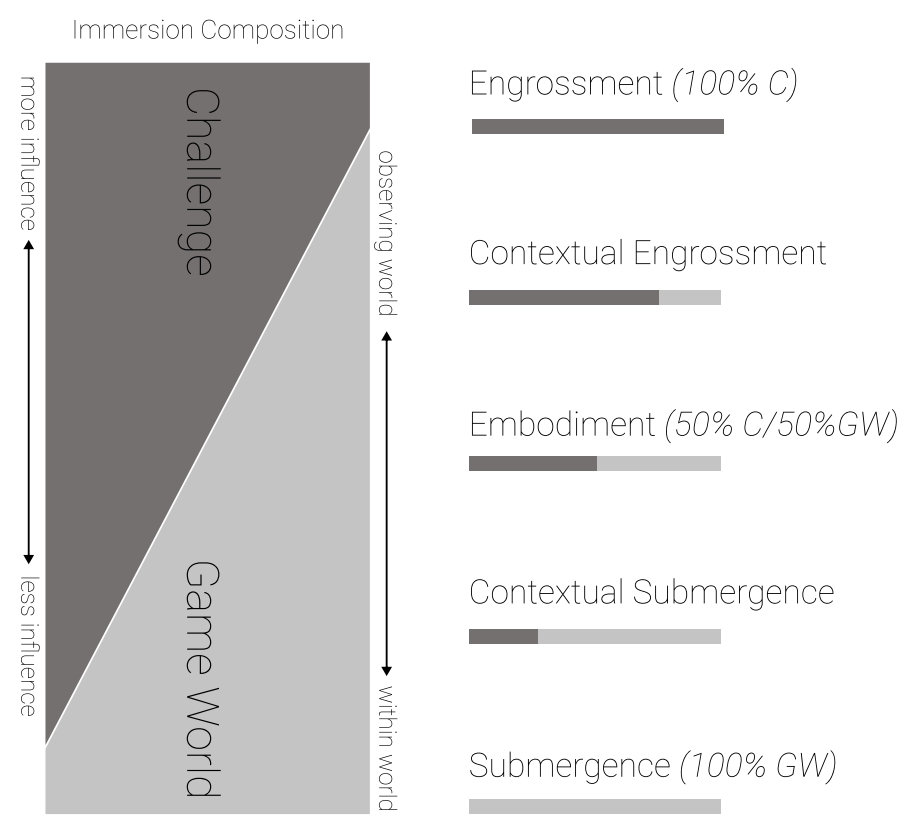

Figure 2: Immersion Experience: Spectrum to show the possible composition of immersive experiences described by board game players.

This was alluded to by one player who reported two games as being "deeply immersive in different ways" [Discussing Terra Mystica and Werewolf].

Through data analysis, we suggest that the relationship between the Conditions Matrix and the Experience Spectrum is causal: when a player's condition(s) for immersion is met by a game, they experience a form of immersion. This experience exists at some point on the Immersion Experience spectrum. While the majority of respondents either described a condition or the nature of the experience, there were examples where a player would nominate both the condition and then provide a description of the resulting experience. One player, for example, describes the Condition to be a certain level of complexity, while the Experience as "being focused": "“[the game should] be so complex that my mind has to be focused on the game at all times". Another player finds "Warhammer Quest: The Silver Tower" to have a "very strong narrative", which in turn results in the experience feeling "like I was an adventurer with my comrades going through a creepy dungeon.” In this case, the Condition is "strong narrative" while the resulting Experience is the Embodiment of an adventurer.

As noted previously, it may be possible for different sets of conditions to lead to different experiences of immersion for players. Therefore it is not a player who occupies a point on the immersive experience spectrum but a combination 
of player and game. For instance, one player may feel immersed playing chess because their required conditions for immersion are that they feel highly challenged and that there are immense amounts of choices available to them. In this instance, the player experiences Engrossment. However they may also have immersion conditions of needing beautiful artwork and well made pieces. These conditions may be met by another game and in this instance the player may experience Embodiment. Here you see the player's position on the immersion experience spectrum alters based upon the game they play and therefore which immersion conditions are met.

\section{Board Game Immersion and Video Game Immersion Theories}

Game properties described by players in In-Game Conditions often correlate with game characteristics found in video game immersion research. While the sensory representation of board games differs from video games in their lack of moving image and (in most cases) audio, it can be argued that players who describe art, game components and theme as their condition for an immersive board game experience are detailing something similar to what Witmer and Singer [66] call a "continuous stream of stimuli". While stimulus provided by board games arguably do not fully surround the player-as identified by Witmer and Singer as a requirement of immersion-we argue that players themselves can provide the "missing piece" either through imagination or through Out-of-Game practices, such as adding music to the game session or otherwise modifying the game environment. Furthermore, these Out-of-Game practices happen whenever the players themselves require them. It is possible for a given game to have met the conditions of immersion as it is for one player (or player group), while at the same time to require Out-of-Game modifications to meet the conditions of another. This suggests that the self-described conditions of immersion differ from player to player, and that players themselves are able to identify whether these conditions have been met or not.

Additionally, similarly to Cairns et al. [14], we suggest that a lack of high visual fidelity of game assets does not prevent players from experiencing immersion whilst playing board games. The aesthetic qualities of game pieces and art are important-and are conditions of immersion to somehowever, what is important to players is that art and components are fitting to the theme of the game and that they are done to high artistic standards.

In video games immersion literature, immersion through sensory elements of video games is often considered as a type of immersion in itself $[28,38,66]$. However, we argue that-at least for board games-sensory elements can be contributing factors in achieving immersion, rather than a type of immersion. This distinction highlights that for some players sensory elements of the board game lead to immersion, but for others they do not. These elements are not immersion but rather are potentially immersive.

Some In-Game Conditions relate to features of board games which provide cognitive challenge to players, such as requiring the game to have strategic depth. Challenge has been recognised as a form of video game immersion [12, 28, 41], and we believe the experience to be similar for board game players. However, we once more distinguish between a requirement of challenge provided by the game as a Condition to immersion, while the feeling of being challenged as the Experience itself. Based on our findings, many players' experiences could be defined as engagement as opposed to immersion. However, as found by Denisova et al. [21], these terminologies overlap when defined by video game players also. We therefore accept engagement as a form of immersion.

World-building and narrative were important to players both in terms of the Conditions needed to achieve immersion, and for the reported experience of immersion. This finding echoes similar results from the video games literature, which highlights the important of world-building for some immersive video game experiences [3, 28, 38, 40].

Our analysis highlights that whilst a game designer can attempt to craft a game world for players to inhabit, the players are still required to acknowledge this in order for the game world to exist. Players who ignore flavour text are perceived to be denying other players of the ability to immerse themselves in the world. Through use of text prompts, game art and mechanics, players create a virtual world in their heads, without needing intense visual stimuli. This is not a unique finding; when considering text-based narrative, Ryan discusses the ability for readers to create their own virtual world in their head from the text alone [52].

This is, however, a difference from video games where world building is presented as a coherent whole through moving image and audio. We argue that board games present more flexibility in the interpretation of the game world, similarly to other text-based media, as suggested by Ryan et al. [52]. Furthermore, this customisation is not just reflected in world building, but how rules are enforced during gameplay, alongside players' ability to introduce Out-of-Game practices. This flexibility of board games suggests that board games allow for a more "customisable" form of immersion, when compared to video game immersion. Video games, on the other hand, present a more homogeneous experience through enforcing the rules and supplying audio-visual stimuli that are specifically designed for the game itself. Whilst board game players can add their own music, for example, it is often "borrowed" from a different domain. 
This contradicts the conclusions that Abeele et al. [1] suggest when considering video game design choices. Abeele et al. propose that game designers have control over aspects of the game which are then entirely responsible for the player experience through functional consequences which lead to emotional consequences. Whilst it seems possible that this is also the case within board games, the analysis in this paper additionally highlights that the existence of immersion is a joint effort between game designer and player, and that regardless of the game designer's choices and decisions, ultimately the player has control over whether those decisions are realised during game play. Further research could determine whether there is a similar, directly casual relationship between Conditions of Immersion and Experiences of Immersion in our work, but importantly the Conditions will include decisions made by both designers and players.

\section{Implications for Designers and Players}

After Dourish [25], we are wary to see Grounded Theory used purely to deliver implications for design. However, this work suggests that board game designers and players might take the following into consideration when thinking about immersion:

- Players can have agency in shaping their experience of immersion as well as the immersion of fellow players. This recognition may lead them, for instance, to consciously choose to act in ways that ensure that immersion is not broken for any of the players.

- Narrative and theme are often identified as primary drivers for immersion; however, we identified other factors (such as time pressure) that designers might consider in order to facilitate different types of immersion.

- Designers might increase immersion by mitigating unwanted player behaviour. One example is players ignoring flavour text, which could be addressed with the inclusion of voice-over, for example.

- Players, as well as designers, should consider that immersion is not experienced the same way by all players. Therefore, a game that is immersive to one player might not be to another.

- Focus and concentration on the game seems to be an important factor across the variety of experiences. Therefore, players-when striving to achieve immersionshould limit distractions during game sessions, whilst designers could consider mitigating the amount of time players need to wait between turns, for instance.

- Whilst it is useful to consider immersion when playing or designing board games, it is apparent that it is not the sole reason why players enjoy board gaming as a hobby.
- Designers could examine Out-of-Game practices that players are choosing to bring to games and consider whether incorporating elements of these practices into new games in a more formal way could increase immersion for other future players. For instance, more game designers may like to consider game soundtrack.

\section{Limitations and Scope of Contributions}

The small sample sizes of the forum data and the interviews prevent us from using these data alone to formulate a fully applicable, general theory of board game immersion. Rather, they have informed an initial understanding of how players experience immersion, in order to identify relevant factors and facets of experience. We have sought to produce useful descriptions of previously unknown phenomena as a basis for further research, alongside demonstrating that players may think about immersion on a wider spectrum than expected.

Whilst hobbyist board game players are arguably more vocal about their play experiences (and it is likely hobbyist board gamers who we have sampled in the forums), these players may not be representative of the wider board game community as a whole. Casual gamers may be more likely to be excluded from these data sets due to not necessarily engaging in the surrounding practices of board gaming the same way as hobbyist gamers do, resulting in a possible over-sampling of hobbyist players. We therefore suggest these theories on board game immersion are preliminary and need validating across a wider variety of gamers. Further, we lack information regarding forum users' backgrounds (e.g., gender, age, and racial representation), so we may have sampling biases in our collection.

Lastly, since one set of data were collected from a prompt question that asked specifically about "what makes you feel like you're in the world", we assume this could be leading people to discuss immersion on the submergence end of the spectrum. However, we don't comment in this paper about the number of participants who report immersion at either end of the spectrum and so feel this does not impact our data analysis overall.

\section{Future Research}

This research highlights that immersion is important to board gamers and that there are distinct definitions for what the experience entails. Whilst completing the analysis we were aware of gaps within our understanding of board game immersion that our theory currently does not explain.

We explored board game immersion from two angles: as a collection of factors which facilitate immersion, together with different ways it manifests for players. However it may be possible that there is a third metric regarding the amount of immersion experienced. We could not extract this information from our current data sets, however, through more 
targeted data collection (such as player interviews) a more complete picture of the board game immersion could be drawn.

Whilst conducting our data analysis we noted that some players made a clear distinction between the concepts of immersion and fun. Whilst many players conflated the two to a certain extent, some players highlighted how separate the two concepts were. One player explained that regardless of how immersive a game is, if it is not fun then immersion alone cannot save it. Conversely another player discussed that strong immersion in a game can overcome negative emotions felt from losing a game. Future research in this area might explore how interrelated immersion and "fun" are within board games.

A final pertinent area for immersion research is the blurring of analogue and digital games. Whilst we have highlighted the differences between the features of board games and video games-such as the materiality of board games or their lack of visual realism-we have not considered digital editions of otherwise analogue games. An increasing number of analogue board games are being translated into a digital form $[4,22,23,29,42]$. While these adaptations aim to implement the mechanics to mimic the analogue version as much as possible, they often feature animations and a soundtrack, which are not present in the original. The question about whether these games are considered more as a video game experience or more as a board game experience could be asked, alongside comparative studies of whether immersion is experienced differently from their analogue original.

\section{CONCLUSION}

In this paper, we show that immersion is an important aspect of the board game experience for many hobbyist players. Just as in video game literature, the term "immersion" has many different definitions for players. Here we have collected and analysed board gamer discussions and interviews to present a Matrix of Conditions of Immersion, alongside a Spectrum of Immersive Experiences. We show that whilst board games and video games have distinct interactive experiences with regard to multimedia, the two seem to elicit similar feelings of immersion according to some definitions of video game immersion. We note that board game players are given somewhat more control over their own immersion however through the ability to add to, ignore, extend, and change aspects of the way a board game is played in a way that may not be as easy within video games.

\section{REFERENCES}

[1] Vero Vanden Abeele, Katta Spiel, Lennart Nacke, Daniel Johnson, and Kathrin Gerling. 2020. Development and validation of the player experience inventory: A scale to measure player experiences at the level of functional and psychosocial consequences. International fournal of
Human Computer Studies 135 (2020), 102370. https://doi.org/10.1016/j. ijhcs.2019.102370

[2] Marco Arnaudo. 2017. The Experience of Flow in Hobby Board Games | Analog Game Studies. http://analoggamestudies.org/2017/11/theexperience-of-flow-in-hobby-board-games/

[3] Dominic Arsenault. [n.d.]. (C) EUROSIS-ETI DARK WATERS: SPOTLIGHT ON IMMERSION. Technical Report. http://www.gamesconference. org/digra2005/viewabstract.

[4] Asmodee Digital. 2015. Splendor. https://www.asmodee-digital.com/ en/splendor/

[5] R. C. (Robert Charles) Bell. 1979. Board and table games from many civilizations (2nd revise ed.). Dover Publications.

[6] BoardGameGeek. 2017. New 'Geek Milestone Reached - 5 million unique visitors in the past 30 days! | Geekdo | BoardGameGeek. https://boardgamegeek.com/thread/1907773/new-geek-milestonereached-5-million-unique-visito

[7] BoardGameGeek. 2017. Which Boardgames Do You Find to be the Most Immersive? | BoardGameGeek | BoardGameGeek. https://boardgamegeek.com/thread/1829382/which-boardgames-doyou-find-be-most-immersive/page/1

[8] Paul Booth. 2015. Game Play : Paratextuality in Contemporary Board Games. Bloomsbury Academic. https://doi.org/10.5040/9781501304972

[9] Paul Booth. 2018. Missing a Piece: (The Lack of) Board Game Scholarship in Media Studies. (2018). https://doi.org/10.7560/VLT8106

[10] Paul Booth. 2019. The Games We Play - Manchester Game Studies Network. https://www.manchestergamestudies.org/blog/2019/7/9/ the-games-we-play

[11] Sarah Lynne Bowman. 2018. Immersion and Shared Imagination in Role-Playing Games. In Role-Playing Game Studies: Transmedia Foundations, José P Zagal and S Deterding (Eds.). Routledge, New York, NY, 379-394. https://www.routledge.com/Role-Playing-GameStudies-Transmedia-

[12] Emily Brown and Paul Cairns. 2004. A Grounded Investigation of Game Immersion. In CHI'04 extended abstracts on Human factors in computing systems. ACM, 1297-1300.

[13] Cameron Browne, Edward Powley, Daniel Whitehouse, Simon Lucas, Senior Member, Peter I Cowling, Philipp Rohlfshagen, Stephen Tavener, Diego Perez, Spyridon Samothrakis, and Simon Colton. 2012. A Survey of Monte Carlo Tree Search Methods. IEEE TRANSACTIONS ON COMPUTATIONAL INTELLIGENCE AND AI IN GAMES 4, 1 (2012). https://doi.org/10.1109/TCIAIG.2012.2186810

[14] Paul Cairns, Anna Cox, and A Imran Nordin. 2014. Immersion in Digital Games: a Review of Gaming Experience Research. In Handbook of Digital Games, Marios C. Angelides and Harry Agius (Eds.). Wiley, Chapter 12, 337-361.

[15] Gordon Calleja. 2007. Games and Culture Digital Game Involvement: A Conceptual Model. 2, 236 (2007). https://doi.org/10.1177/ 1555412007306206

[16] Gordon Calleja. 2011. In-game: From immersion to incorporation. MIT Press.

[17] Cathy Charmaz. 2013. Constructing Grounded Theory (Introducing Qualitative Methods series) (2nd ed.). SAGE Publications Ltd, London. 416 pages.

[18] Judith A. Chevalier and Dina Mayzlin. 2003. Te Effect of Word of Mouth on Sales: Online Book Reviews. (2003). https://doi.org/10.1509/ jmkr.43.3.345 arXiv:0022-2437

[19] David Cicurel. 2018. Chronicles of Crime.

[20] Alena Denisova and Paul Cairns. 2015. (2015). https://doi.org/10.1145/ 2702123.2702256

[21] Alena Denisova, A Imran Nordin, and Paul Cairns. 2016. The Convergence of Player Experience Questionnaires. (2016). https://doi.org/10. $1145 / 2967934.2968095$ 
[22] DIGIDICED. 2017. Cottage Garden. https://digidiced.com/cottagegarden/

[23] DIGIDICED. 2019. The Castles Of Burgundy. https://play.google.com/ store/apps/details?id=com.digidiced.bvbrelease $\{\&\} \mathrm{hl}=\mathrm{en}\left\{\_\right\} \mathrm{GB}$

[24] Yellowlees Douglas and Andrew Hargadon. 2000. The Pleasure Principle: Immersion, Engagement, Flow. Technical Report.

[25] Paul Dourish. 2006. Implications for Design. Technical Report.

[26] Druid City Games. 2019. Tidal Blades - Heroes of the Reef by Druid City Games. https://www.kickstarter. com/projects/druidcitygames/tidal-blades-heroes-of-thereef?ref=discovery $\{\&\}$ term=immersiveboardgame

[27] Andrew Epps, Samira Dhoparee, Tim Tijs, Anna L. Cox, Charlene Jennett, Alison Walton, and Paul Cairns. 2008. Measuring and defining the experience of immersion in games. International fournal of HumanComputer Studies 66, 9 (2008), 641-661. https://doi.org/10.1016/j.ijhcs. 2008.04.004

[28] Laura Ermi and Frans Mayra. 2007. Fundamental Components of the Gameplay Experience. Worlds in Play: International Perspectives on Digital Games and Research (2007), 37-54.

[29] Funforge Digital. 2017. Tokaido Digital.

[30] Fernand. Gobet, Alexander J. de. Voogt, and Jean. Retschitzki. 2004. Moves in mind : the psychology of board games (1st ed.). Psychology Press.

[31] Charlie Hall. 2018. Kickstarter games in 2018: Tabletop game dominated, video games declined. https:/www.polygon.com/2019/1/15/ 18184108/kickstarter-2018-stats-tabletop-video-games

[32] Charlene Jennett, Anna L. Cox, Paul Cairns, Samira Dhoparee, Andrew Epps, Tim Tijs, and Alison Walton. 2008. Measuring and defining the experience of immersion in games. International fournal of Human Computer Studies 66, 9 (sep 2008), 641-661. https://doi.org/10.1016/j. ijhcs.2008.04.004

[33] Charlene Ianthe Jennett. 2010. Is game immersion just another form of selective attention? An empirical investigation of real world dissociation in computer game immersion. Ph.D. Dissertation. UCL (University College London).

[34] Mehmet Kosa and Pieter Spronck. 2018. What tabletop players think about augmented tabletop games. Proceedings of the 13th International Conference on the Foundations of Digital Games - FDG '18 (2018), 1-8. https://doi.org/10.1145/3235765.3235782

[35] Matúš Kotry. 2014. Alchemists.

[36] Aleks Krotoski and John Oates. 2017. Ethics Guidelines for Internet-mediated Research. Technical Report. www.bps.org.uk/publications/policy-and-guidelines/researchguidelines-policy-documents/research-guidelines-poli

[37] Ryan Laukat. 2015. Above and Below. https://boardgamegeek.com/ boardgame/172818/above-and-below

[38] Alison McMahan. 2003. Immersion, Engagement, and Presence. In The video game theory reader. 67-86.

[39] Alison McMahan. 2003. Immersion, engagement and presence. The video game theory reader 67 (2003), 86.

[40] Janet Horowitz Murray and Janet H Murray. 2017. Hamlet on the holodeck: The future of narrative in cyberspace. MIT press.

[41] Niels Christian Nilsson, Rolf Nordahl, and Stefania Serafin. 2016. Immersion revisited: A review of existing definitions of immersion and their relation to different theories of presence. Human Technology 12 , 2 (2016), 108-134. https://doi.org/10.17011/ht/urn.201611174652

[42] Nintendo. 2020. WINGSPAN for Nintendo Switch . https://www. nintendo.com/games/detail/wingspan-switch/

[43] David Parlett. 2018. Parlett's history of board games (2nd ed.). 387 pages.

[44] Portal Games. 2018. Detective: A Modern Crime Board Game Official Homepage. https://detectiveboardgame.com/
[45] Reddit. 2017. What is the most immersive game you have ever played? : boardgames. https: //www.reddit.com/r/boardgames/comments/4y4fyn/ what \{_\}is\{_\}the \{_\}most__\}immersive \{_\}game\{_\}you\{_\}have\{_\}ever/

[46] Reddit. 2017. What is the most immersive game you've played? What game really makes you feel like you are in that world? : boardgames. https://www.reddit.com/r/boardgames/comments/ 5y0ofh/what_is_the_most_immersive_game_youve_played_what

[47] Reddit. 2019. boardgames. https://www.reddit.com/r/boardgames/

[48] Melissa J Rogerson and Martin Gibbs. 2018. Finding Time for Tabletop: Board Game Play and Parenting. (2018). https://doi.org/10.1177/ 1555412016656324

[49] Melissa J. Rogerson, Martin Gibbs, and Wally Smith. 2016. "I Love All the Bits". (2016), 3956-3969. https://doi.org/10.1145/2858036.2858433

[50] Melissa J. Rogerson, Martin Gibbs, and Wally Smith. 2017. Exploring the Digital Hinterland: Internet Practices Surrounding The Pursuit of "Offline" Hobbies. Technical Report. http://spir.aoir.org.

[51] Melissa J Rogerson, Martin R Gibbs, and Wally Smith. 2018. Cooperating to Compete: the Mutuality of Cooperation and Competition in Boardgame Play. Proc. of CHI (2018), 1-13. https://doi.org/10.1145/ 3173574.3173767

[52] Marie-Laure Ryan. 2001. Narrative as Virtual Reality Immersion and Interactivity in Literature and Electronic Media. Technical Report. www.press.jhu.edu

[53] Przemysław; Rymer, Ignacy; Trzewiczek, and Jakub Łapot. 2018. Detective: A Modern Crime Board Game.

[54] Katie Salen, Katie Salen Tekinbaş, and Eric Zimmerman. 2004. Rules of play: Game design fundamentals. MIT press.

[55] Michael Sebbane. 2001. Board Games from Canaan in the Early and Intermediate Bronze Ages and the Origin of the Egyptian Senet Game. Journal of the Institute of Archeology of Tel Aviv University 28, 2 (2001), 213-230. https://doi.org/10.1179/tav.2001.2001.2.213

[56] Niki Shults. 2020. Introducing Forgotten Waters! https://www. plaidhatgames.com/news/1045

[57] Robert S. Siegler and Geetha B. Ramani. 2008. Playing linear numerical board games promotes low-income children's numerical development. Developmental Science 11, 5 (sep 2008), 655-661. https://doi.org/10. 1111/j.1467-7687.2008.00714.x

[58] David Silver, Aja Huang, Chris J Maddison, Arthur Guez, Laurent Sifre, George Van Den Driessche, Julian Schrittwieser, Ioannis Antonoglou, Veda Panneershelvam, Marc Lanctot, Sander Dieleman, Dominik Grewe, John Nham, Nal Kalchbrenner, Ilya Sutskever, Timothy Lillicrap, Madeleine Leach, Koray Kavukcuoglu, Thore Graepel, and Demis Hassabis. 2016. Mastering the game of Go with deep neural networks and tree search. Nature 529 (2016). https://doi.org/10.1038/ nature 16961

[59] Mel Slater. 2003. A note on presence terminology. Presence connect 3, 3 (2003), 1-5.

[60] Steamforged Games Ltd. 2016. Dark Souls ${ }^{\mathrm{TM}}$ - The Board Game by Steamforged Games Ltd. https://www.kickstarter.com/projects/ steamforged/dark-soulstm-the-board-game?ref=discovery $\{\&\}$ term= immersiveboardgame

[61] Nikki Valens. 2016. Mansions of Madness: Second Edition.

[62] Friedhelm Merz Verlag. 2020. Exhibitors - SPIEL Messe. https: //www.spiel-messe.com/en/exhibitors/

[63] Paul Wake. 2019. Token Gestures: Towards a Theory of Immersion in Analog Games | Analog Game Studies. Analog Game Studies fournal VI, III (2019). http://analoggamestudies.org/2019/09/token-gesturestowards-a-theory-of-immersion-in-analog-games/

[64] Gareth White. 2012. On Immersive Theatre. Theatre Research International 37, 3 (2012), 221-235. https://doi.org/10.1017/ S0307883312000880 
[65] Helene Whittaker. 2005. Board games and funerary symbolism in Greek and Roman contexts 1. Technical Report. https://digitalt.uib.no/ bitstream/handle/1956.2/2965/Board?sequence=1

[66] Bob G. Witmer and Michael J. Singer. 1998. Measuring Presence in Virtual Environments: A Presence Questionnaire. Presence 7, 3 (1998),
225-240. https://doi.org/10.1117/12.2233447

[67] Feng Zhu and Xiaoquan(Michael) Zhang. 2006. The Influence of Online Consumer Reviews on the Demand for Experience Goods: The Case of Video Games. International Conference on Information Systems(ICIS) (2006), 17. https://doi.org/10.1016/S0166-4328(01)00353-9 